\title{
EFEKTIVITAS CAMPURAN SAMPAH KUBIS DAN DAUN MANGGA SEBAGAI KOMPOS DENGAN VARIASI AKTIVATOR
}

KartikaDamayanti, Mujiyono, Handoyo

\begin{abstract}
Magetan society rarely take advantage of the organic waste. So it is necessary to do research on composting. This study aims to determine the effectiveness of sewage treatment using cabbage and mango leaves as main material and activator used were cow dung, goat dung and EM4.

This is a pre-experimental research. Data collected by the experiment, measured and observed. 27 samples of 3 diferent-processes were 9 sample using cow manure activators, 9 second sample using goat droppings activator and 9 third sample using activator EM4. The data were then analyzed by calculating the average weight reduction of waste.Analyses using ANOVA test.

Based on the result of statistical test, it is known $\rho$ sign $0,000<a(0,01)$ so that $H_{1}$ is accepted or no difference to the effectiveness on variation activator mixture of cabbage and mango leaves as compost. The results showed that the use of cow dung activators weight decreased $28.20 \%$, temperature (27-37) ${ }^{\circ} \mathrm{C}, \mathrm{pH}(6.6$ to 7$)$, humidity (55-70)\%. The use of goat dung activators weight down $40.90 \%$, temperature (28-39) ${ }^{\circ} \mathrm{C}, \mathrm{pH}(6.7$ to 7$)$, humidity (65-75)\%. The use of EM4 weight decreased 61\%, temperature (27-40) ${ }^{\circ} \mathrm{C}, \mathrm{pH}(6.6$ to 7$)$, humidity (55-75)\%.

We recommend using EM4 activatorbecause the result is the best. Keep the temperature and humidity so that the composting process is going well.
\end{abstract}

Keywords : effectiveness, cabbage, mango leaves, composting, variation of activator

\section{PENDAHULUAN}

Sampah menjadi masalah penting di daerah yang berpenduduk padat yang disebabkan oleh beberapa faktor diantaranya volume sampah yang sangat besar dan tidak dimanfaatkan dengan baik oleh manusia.

Berdasarkan pengamatan yang dilakukan, jenis sampah yang paling banyak untuk daerah Magetan yaitu sampah organik. Masih sangat jarang sekali masyarakat Magetan memanfaatkan sampah-sampah organik tersebut.

Untuk mengatasi hal tersebut, perlu dilakukan penelitian yang dapat mengubah sampah organik menjadi sesuatu yang bermanfaat untuk manusia. Salah satunya adalah memanfaatkan sampah organik yaitu sisa sayuran untuk bahan pembuatan kompos sehingga sampah sisa sayuran tidak terbuang sia-sia.

Berdasarkan latar belakang tersebut diatas, perludilakukan Uji Coba Efektivitas Campuran Sampah Kubis dan Daun Mangga sebagai Kompos dengan Menggunakan Variasi Aktivator. Tujuan Penelitian adalah: Menilai perbandingan efektivitas sistem pengomposan sampah Kubis dan Daun Mangga dengan Aktivator Kotoran Sapi, Kotoran Kambing dan EM4.

\section{METODE PENELITIAN}

Jenis penelitian dalam penelitian ini adalah pre-eksperimentkarena desain percobaan yang tidak mencukupi semua syarat-syarat dari suatu desain percobaan sebenarnya. Dalam penelitian ini akan dilakukan percobaan untuk mengetahui perbedaan efektivitas pembuatan kompos dengan tiga aktivator yang berbeda.

Objek dalam penelitian ini adalah sampah kubis dan daun mangga serta aktivator yang digunakan adalah kotoran sapi, kotoran kambing, dan larutan EM4.

\section{HASIL PENELITIAN dan Pembahasan}

\section{Pelaksanaan Pembuatan Kompos}

Pembuatan kompos dilaksanakan pada tanggal 14 Maret 2015 di bengkel Prodi DIII Kesehatan Lingkungan Kampus Magetan. Langkah pertama yang dilakukan dalam pembuatan kompos adalah mengumpulkan bahan pembuatan kompos yaitu kubis, daun mangga, kotoran sapi, dan kotoran kambing. Setelah kubis dan daun mangga terkumpul, selanjutnya daun dicacah. Bahan organik yang telah dicacah dibagi menjadi 27 sampel dan diperoleh berat sampah organik setiap sampel $2 \mathrm{~kg}$. 9 sampel pertama (perlakuan I) ditambahkan aktivator kotoran sapi, 9 
sampel kedua (perlakuan II) ditambahkan aktivator kotoran kambing, dan 9 sampel ketiga (perlakuan III) ditambahkan aktivator EM4. Menurut perhitungan,daun mangga mempunyai C/N sebesar 40/1, kubis 12/1, kotoran sapi yang sudah terurai menyerupai tanah 25/1, dan kotoran kambing yang sudah terurai dan menyerupai tanah $25 / 1$.

Berat aktivator kotoran sapi yang dibutuhkan 3,2 kg, dan berat aktivator kotoran kambing yang dibutuhkan 2,4 kg. Proses pembuatan kompos dibatasi waktu yaitu selama 30 hari. Selama proses pengomposan harus dilakukan pengukuran suhu, pH dan kelembaban. Setelah proses pengomposan selesai kompos kemudian ditimbang.

Pembuatan kompos menggunakan bahan organik sampah kubis dan daun mangga. Setelah terkumpul bahan organik tersebut dicacah dan dilakukan penambahan aktivator kotoran sapi, kotoran kambing, dan EM4, kemudian diwadahi menggunakan karung. Setiap aktivator terdiri dari 9 sampel. 9 sampel pertama ditambahkan aktivator kotoran sapi, 9 sampel kedua ditambahkan aktivator kotoran kambing, 9 sampel ketiga ditambahkan aktivator EM4. Proses pembuatan kompos membutuhkan waktu 30 hari. Setelah proses pengomposan selesai kompos kemudian ditimbang.

Temperatur merupakan faktor penting penentu pertumbuhan mikroorganisme pengurai kompos. Temperatur tumpukan kompos terbaik adalah $(50-55)^{\circ} \mathrm{C}$. Kisaran temperatur yang dijinkan yaitu $(45-80)^{\circ} \mathrm{C}$. Jika temperatur terlalu rendah dapat menyebabkan mikroorganisme dekomposer tidak akan aktif sehingga proses pengomposan membutuhkan waktu yang lama (Happy Mulyani, 2014). Temperatur kompos dengan aktivator kotoran sapi yaitu antara (27$37)^{\circ}$, aktivator kotoran kambing (28$39)^{\circ} \mathrm{C}$, dan EM4 antara $(27-40)^{\circ} \mathrm{C}$. Temperatur ini tidak sesuai dengan teori (Happy Mulyani, 2014). Temperatur ini masih dibawah suhu terbaik sehingga mikroorganisme belum bisa bekerja dengan optimal.

Kelembaban memegang peranan yang sangat penting dalam proses metabolisme mikroorganisme. Kelembaban dalam tumpukan sampah sebaiknya dijaga selalu berada dalam kisaran (50-60)\% supaya aktivitas mikroorganisme aerob bekerja optimal (Happy Mulyani, 2014).

Untuk menjaga kelembaban selama proses pengomposan, tiga hari sekali dilakukan pemantauan, untuk kompos yang kering ditambahkan air dan untuk kompos yang sangat basah dijemur untuk mengurangi kadar air didalamnya.

Kelembaban kompos menggunakan aktivator kotoran sapi yaitu antara (5570) \%. Kelembaban pada saat awal pembuatan kompos yaitu 70\%, aktivator kotoran kambing yaitu antara (65-75) \%. Kelembaban pada saat awal pembuatan kompos yaitu 65\%. Aktivator EM4 antara (55-75) \%. Kelembaban pada saat awal pembuatan kompos yaitu $65 \%$. Hal ini tidak sesuai (Happy Mulyani, 2014). Kelembaban tersebut tinggi karena terlalu banyak air yang diberikan pada saat pencampuran bahan. Telah dilakukan upaya untuk munurunkan kelembaban yaitu kompos menggunakan aktivator kotoran sapi dan kotoran kambing dengan cara diangin-anginkan, dan untuk EM4 dijemur selama kurang lebih 5menit. Meskipun telah dilakukan upaya tersebut kelembaban masih tinggi. Apabila kelembaban lebih dari $60 \%$ maka mikroorganisme kurang bekerja dengan optimal.

$\mathrm{pH}$ dapat dijadikan sebagai indikator kehidupan mikroorganisme. Rentang $\mathrm{pH}$ tumpukan kompos sebaiknya dipertahankan berkisar antara $7-7,5$ (Happy Mulyani, 2014) sesuai dengan pH yang dibutuhkan tanaman.

$\mathrm{pH}$ kompos menggunakan aktivator kotoran sapi antara (6,6-7), aktivator kotoran kambing yaitu $(6,7-7)$, aktivator EM4 yaitu 7. Hal ini tidak sesuai berdasarkan (Happy Mulyani, 2014), tetapi perbedaannya tidak terlalu jauh.
Perubahan Fisik Kompos

1. Aktivator Kotoran Sapi 
TABEL 1 HASIL PENGAMATAN PERUBAHAN FISIK KOMPOS SELAMA PROSES PENGOMPOSAN MENGGUNAKAN AKTIVATOR KOTORAN SAPI

\begin{tabular}{|l|l|l|}
\hline No. & Hari ke- & Perubahan Fisik \\
\hline 1. & 1 & Warna hijau segar, tekstur utuh dan keras \\
\hline 2. & 4 & Warna hijau layu, tekstur utuh dan keras \\
\hline 3. & 7 & Warna hijau layu, tekstur utuh dan keras \\
\hline 4. & 10 & Warna hijau layu, tekstur utuh dan keras \\
\hline 5. & 13 & Warna hijau layu kecoklatan, tekstur utuh dan keras \\
\hline 6. & 16 & Warna hijau layu kecoklatan, tekstur utuh dan keras \\
\hline 7. & 19 & Warna hijau layu kecoklatan, tekstur utuh dan keras \\
\hline 8. & 22 & Warna kecoklatan, tekstur mudah hancur \\
\hline 9. & 25 & Warna hitam kecoklatan, tekstur mudah hancur \\
\hline 10. & 28 & Warna hitam kecoklatan, tekstur mudah hancur \\
\hline 11. & 30 & Warna hitam kecoklatan, tekstur mudah hancur \\
\hline
\end{tabular}

2. Aktivator Kotoran Kambing

TABEL 2 HASIL PENGAMATAN PERUBAHAN FISIK KOMPOS SELAMA PROSES PENGOMPOSAN MENGGUNAKAN AKTIVATOR KOTORAN KAMBING

\begin{tabular}{|l|l|l|}
\hline No. & Hari ke- & Perubahan Fisik \\
\hline 1. & 1 & Warna hijau segar, tekstur utuh dan keras \\
\hline 2. & 4 & Warna hijau layu, tekstur utuh dan keras \\
\hline 3. & 7 & warna hijau layu, tekstur utuh dan keras \\
\hline 4. & 10 & Warna hijau layu kecoklatan, tekstur utuh dan keras \\
\hline 5. & 13 & Warna hijau layu kecoklatan, tekstur utuh dan keras \\
\hline 6. & 16 & Warna hijau layu kecoklatan, tekstur utuh dan keras \\
\hline 7. & 19 & Warna kecoklatan, tekstur mudah hancur \\
\hline 8. & 22 & Warna kecoklatan, tekstur mudah hancur \\
\hline 9. & 25 & Warna kecoklatan, tekstur mudah hancur \\
\hline 10. & 28 & Warna hitam kecoklatan, tekstur mudah hancur \\
\hline 11. & 30 & Warna hitam kecoklatan, tekstur mudah hancur \\
\hline
\end{tabular}

3. Aktivator EM4

TABEL 3 HASIL PENGAMATAN PERUBAHAN FISIK KOMPOS SELAMA PROSES PENGOMPOSAN MENGGUNAKAN AKTIVATOR EM4

\begin{tabular}{|l|l|l|}
\hline No. & Hari ke- & Perubahan Fisik \\
\hline 1. & 1 & Warna hijau segar, tekstur utuh dan keras \\
\hline 2. & 4 & Warna hijau segar, tekstur utuh dan keras \\
\hline 3. & 7 & Warna hijau segar, tekstur utuh dan keras \\
\hline 4. & 10 & Warna hijau layu, tekstur utuh dan keras \\
\hline 5. & 13 & Warna hijau layu, tekstur utuh dan keras \\
\hline 6. & 16 & Warna hijau layu, tekstur utuh dan keras \\
\hline 7. & 19 & Warna hijau kecoklatan, tekstur utuh dan keras \\
\hline 8. & 22 & Warna hijau kecoklatan, tekstur mudah hancur \\
\hline 9. & 25 & Warna kecoklatan, tekstur mudah hancur \\
\hline 10. & 28 & Warna hitam kecoklatan, tekstur mudah hancur \\
\hline 11. & 30 & Warna hitam kecoklatan, tekstur mudah hancur \\
\hline
\end{tabular}

Penurunan Berat Kompos

1. Aktivator Kotoran Sapi 
TABEL 4

HASIL PENGUKURAN PENURUNAN BERAT KOMPOS MENGGUNAKAN AKTIVATOR KOTORAN SAPI

\begin{tabular}{|c|c|c|c|c|}
\hline $\begin{array}{l}\bar{y} \\
\frac{1}{1} \\
\frac{1}{0} \\
\frac{0}{\alpha}\end{array}$ & 芯哥 & 荌 吾 & 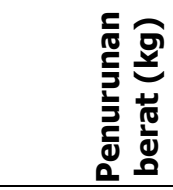 & 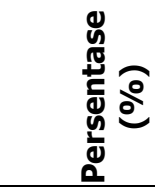 \\
\hline 1 & 5,2 & 3,50 & 1,70 & 32,69 \\
\hline 2 & 5,2 & 3,80 & 1,40 & 26,92 \\
\hline 3 & 5,2 & 3,50 & 1,70 & 32,69 \\
\hline 4 & 5,2 & 3,80 & 1,40 & 26,92 \\
\hline 5 & 5,2 & 4,00 & 1,20 & 23,07 \\
\hline 6 & 5,2 & 3,80 & 1,40 & 26,92 \\
\hline 7 & 5,2 & 4,00 & 1,20 & 23,07 \\
\hline 8 & 5,2 & 3,70 & 1,50 & 28,84 \\
\hline 9 & 5,2 & 3,50 & 1,70 & 32,69 \\
\hline Rata-rata & 5,2 & 3,73 & 1,46 & 28,20 \\
\hline
\end{tabular}

2. Aktivator Kotoran Kambing

TABEL 5

HASIL PENGUKURAN PENURUNAN BERAT KOMPOS MENGGUNAKAN AKTIVATOR KOTORAN KAMBING

\begin{tabular}{|c|c|c|c|c|}
\hline 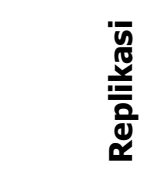 & 节疍 & 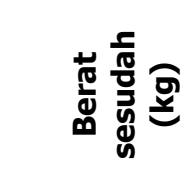 & 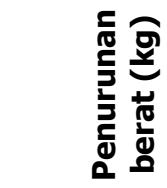 & 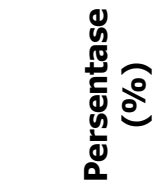 \\
\hline 1 & 4,4 & 2,50 & 1,90 & 43,18 \\
\hline 2 & 4,4 & 2,50 & 1,90 & 43,18 \\
\hline 3 & 4,4 & 2,80 & 1,60 & 36,36 \\
\hline 4 & 4,4 & 2,80 & 1,60 & 36,36 \\
\hline 5 & 4,4 & 2,80 & 1,60 & 36,36 \\
\hline 6 & 4,4 & 2,50 & 1,90 & 43,18 \\
\hline 7 & 4,4 & 2,40 & 2,00 & 45,45 \\
\hline 8 & 4,4 & 2,30 & 2.10 & 47,72 \\
\hline 9 & 4,4 & 2,80 & 1,60 & 36,36 \\
\hline 密丞 & 4,4 & 2,60 & 1,80 & 40,90 \\
\hline
\end{tabular}


3. Aktivator EM4

TABEL 6 HASIL PENGUKURAN PENURUNAN BERAT KOMPOS MENGGUNAKAN AKTIVATOR EM4

\begin{tabular}{|c|c|c|c|c|}
\hline 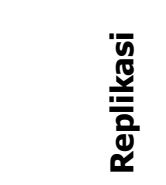 & 劳竞 & 芯莡 & 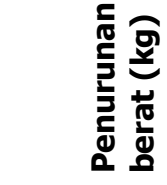 & 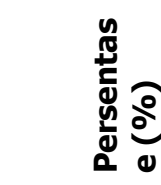 \\
\hline 1 & 2,0 & 0,80 & 1,20 & 60 \\
\hline 2 & 2,0 & 0,85 & 1,15 & 57,50 \\
\hline 3 & 2,0 & 0,85 & 1,50 & 57,50 \\
\hline 4 & 2,0 & 0,80 & 1,20 & 60 \\
\hline 5 & 2,0 & 0,90 & 1,10 & 55 \\
\hline 6 & 2,0 & 0,75 & 1,25 & 62,50 \\
\hline 7 & 2,0 & 0,80 & 1,20 & 60 \\
\hline 8 & 2,0 & 0,85 & 1.15 & 57,50 \\
\hline 9 & 2,0 & 0,85 & 1,15 & 57,50 \\
\hline 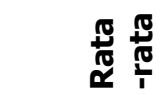 & 2,0 & 0,82 & 1,21 & 58,61 \\
\hline
\end{tabular}

\section{Perubahan Fisik Kompos}

Pembuatan kompos dengan menggunakan aktivator kotoran sapi mengalami perubahan fisik yaitu berwarna hijau segar hingga hijau layu, tekstur utuh dan keras terjadi pada hari pertama sampai hari ke-10. Berwarna hijau layu kecoklatan, tekstur utuh dan keras terjadi pada hari ke-13 sampai hari ke-19 dan berwarna kecoklatan hingga hitam kecoklatan, tekstur mudah hancur terjadi pada hari ke-22 sampai hari ke30.

Menggunakan aktivator kotoran kambing mengalami perubahan fisik yaituberwarna hijau segar hingga hijau layu, tekstur utuh dan keras terjadi pada hari pertama hingga hari ke-7. Berwarna hijau layu kecoklatan, tekstur utuh dan keras terjadi pada hari ke-10 sampai hari ke-16. Berwarna kecoklatan, tekstur mudah hancur terjadi pada hari ke-19 sampai hari ke-25 dan berwarna hitam kecoklatan, tekstur mudah hancur terjadi pada hari ke-28 sampai hari ke-30.

Aktivator EM4 mengalami perubahan fisik yaituberwarna hijau segar hingga hijau layu, tekstur utuh dan keras terjadi pada hari pertama hingga hari ke-16. Berwarna hijau kecoklatan hingga kecoklatan, tekstur utuh dan keras hingga mudah hancur terjadi pada hari ke-19 sampai hari ke-25. Berwarna hijau hitam kecoklatan, tekstur mudah hancur terjadi pada hari ke-28 sampai hari ke-30
Dengan demikian pembuatan kompos dengan menggunakan aktivator kotoran kambing lebih cepat mengalami perubahan fisik. Hal tersebut dapat terjadi karena peran penting suhu yang menandakan mikroorganisme didalamnya bekerja dengan baik. Sedangkan perubahan fisik yang memerlukan waktu paling lama dibangdingkan aktivator lain adalah pembuatan kompos menggunakan aktivator EM4 dikarenakan temperatur pada saat awal pengomposan belum optimal sehingga bakteri didalamnya belum aktif.

\section{Penurunan Berat Kompos}

Pembuatan kompos dengan menggunakan aktivator kotoran sapi rata-rata beratnya turun $28,20 \%$ dari berat awal, temperatur maksimal hanya $37^{\circ} \mathrm{C}$, pH antara $(6,6-7)$ dan kelembaban (55-70)\%. Aktivator kotoran kambing rata-rata beratnya turun $40,90 \%$ dari berat awal, temperatur yaitu $(28-39)^{\circ} \mathrm{C}$, $\mathrm{pH}$ antara (6,7-7), dan kelembaban (65$75) \%$. Aktivator EM4 beratnya turun hingga rata-rata $58,61 \%$, dengan temperatur $(27-40)^{\circ} \mathrm{C}, \mathrm{pH}(6,6-7)$, dan kelembaban (55-75)\%. Temperatur tersebut kurang optimal sehingga penurunan berat hanya sedikit. Penurunan berat yang tidak sesuai yaitu menggunakan aktivator kotoran sapi, dan penggunaan aktivator yang sesuai yaitu kotoran kambing dan EM4. Penurunan berat yang baik seharusnya sepertiga dari berat awal. 
Analisis Perbedaan Variasi Aktivator terhadap pembuatan Kompos

Berdasarkan hasil uji statistik (hasil terlampir) diketahui bahwa $\rho$ sign $0,000<a(0,01)$ sehingga $H_{1}$ diterima atau ada perbedaan efektivitas variasi aktivator terhadap campuran kubis dan daun mangga sebagai kompos. Berdasarkan hasil analisis tersebut menunjukkan adanya perbedaan aktivator dalam penurunan berat sampah selama proses pengomposan. Penurunan berat dari masing masing aktivator menunjukkan perbedaan dimana yang paling banyak mengalami penurunan berat adalah kompos dengan aktivator EM4. EM4 dapat menurunkan berat kompos lebih banyak karena unsur-unsur yang terdapat dalam EM-4 meliputi bakteri penghasil asam laktat Lactobacillus sp., bakteri fotosintetik Streptomyces sp., ragi (yeast), dan Actinomycetes (Happy Mulyani, 2014). Unsur hara yang terdapat pada kotoran sapi yaitu $\mathrm{H}_{2} \mathrm{O}, \mathrm{N}, \mathrm{P}_{2} \mathrm{O}_{5}$, dan $\mathrm{K}_{2} \mathrm{O}$. Dan unsur hara yang terdapat pada kotoran kambing yaitu $\mathrm{H}_{2} \mathrm{O}, \mathrm{N}, \mathrm{P}_{2} \mathrm{O}_{5}$, dan menyediakan unsur hara tersedia bagi tanaman berlangsung cepat. Jasad renik melakukan perubahan-perubahan aktif disertai pembentukan panas. (Rizki Ramadhani,2013), sehingga pembuatan kompos dengan menggunakan aktivator kotoran kambing juga dapat menurunkan berat kompos lebih banyak. Temperatur yang kurang maksimal mempengaruhi kerja bakteri yang ada di dalam kompos yaitu, temperatur kotoran sapi antara(27-37) ${ }^{\circ}$, aktivator kotoran kambing $(28-39)^{\circ} \mathrm{C}$, dan EM4 antara $(27-40)^{\circ} \mathrm{C}$. Penggunaan aktivator kotoran kambing dan EM4 mengalami penurunan berat yang cukup karena dipengaruhi oleh temperatur yang cukup baik jika dibandingan dengan menggunakan aktivator kotoran sapi. Jumlah sampel aktivator kotoran api, kotoran kambing dan EM4 yaitu 9, total yaitu 27 sampel. Penurunan berat rata-rata aktivator kotoran sapi 28.2011, aktivator kotoran kambing 40.9056, dan EM4 58.6111. Penurunan berat minimum aktivator kotoran sapi 23.07, kotoran kambing 36.36, EM4 55.00. Penurunan berat maksimum aktivator kotoran sapi 32.69, kotoran kambing 47.72, EM4 62.50 .

\section{KESIMPULAN}

1. Pengomposan sampah organik dengan penambahan aktivator kotoran sapi mengalami penurunan berat rata-rata $1,46 \mathrm{~kg}$ atau $28,20 \%$ dari berat awal. Aktivator ini kurang efektif digunakan sebagai aktivator pembuatan kompos.

2. Penambahan aktivator kotoran kambing mengalami penurunan berat yaitu rata-rata $1,80 \mathrm{~kg}$ atau $40,90 \%$ dari berat awal. Aktivator ini efektif digunakan dalam pembuatan kompos, karena penurunan berat rata-rata $40,90 \%$.

3. Penambahan aktivator EM4 menghasilkan penurunan berat yaitu rata-rata $1,21 \mathrm{~kg}$ atau $58,61 \%$ dari berat awal. Sehingga aktivator ini dinyatakn paling efektif dalam pembuatan kompos karena penurunan berat cukup besar.

\section{SARAN}

1. Dalam pembuatan kompos yang efektif sebaiknya menambahkan kotoran kambing sebagai aktivator karena dapat menurunkan berat lebih banyak dan sebagai alternatif selain EM4 yang membutuhkan biaya lebih besar.

2. Bahan yang akan digunakan untuk membuat kompos sebaiknya dalam jumlah yang banyak agar proses pengomposan lebih maksimal.

3. Mencacah bahan organik sekecil mungkin agar mikroorganisme mengurai bahan organik lebih cepat.

4. Pertahankan suhu dan kelembaban agar proses pengomposan berjalan dengan baik.

5. Sebaiknya aktivator kotoran sapi dan kambing dikendalikan sampai matang dan siap digunakan sebagai aktivator.

6. Bagi peneliti lain, dapat melakukan penelitian kandungan bakteri yang ada dalam kotoran sapi dan kotoran kambing.

\section{DAFTAR PUSTAKA}

Chandra, Budiman, 2005. Pengantar Kesehatan Lingkungan. Jakarta, Penerbit Buku Kedokteran EGC.

Djaja, Willyan , Cet.1 2008. Langkah Jitu Membuat Kompos dari Kotoran Ternak dan Sampah. Jakarta, PT. AgroMedia Pustaka.

Handoyo, 2005. Pedoman Pembuatan Kompos Bagi Mahasiswa Program Studi D-III Kesehatan Lingkungan Magetan. 
Hasanah, Iswatun, 2010. Uji Efektivitas Pembuatan Kompos dengan Tiga Aktivator terhadap Pengurangan Timbulan Sampah di Pasar Mangge Kec.Barat Kab.Magetan.

Indriani, Yovita Hety, 1999, Membuat Kompos Secara Kilat. Depok, Penebar Swadaya.

Mulyani, Happy, Cet.1 2014. Optimasi Perancangan Model Pengomposan. Jakarta, CV. Trans Info Media

Notoatmodjo, Soekidjo, Cet.1 1993. Metode Penelitian Kesehatan. Jakarta, PT.RINEKA CIPTA.

Oktora, Nanda, 2013. Klasifikasi dan Morfologi.http://www.petani hebat.com/2013/10/klasifika si-dan-morfologi-tanamanmangga.html

Rahayu, Purwaningsih dan Pujianto, 2009. PEMANFAATAN KOTORAN TERNAK SAPI SEBAGAI SUMBER ENERGI ALTERNATIF RAMAH LINGKUNGAN BESERTA ASPEK SOSIO KULTURALNYA*). journal.uny.ac.id/index.php/i notek/article/download/38/1 3

Ramadhani, Rizki, 2012. PUPUK DAN TEKNOLOGI PEMUPUKAN
"KOSAMBIRAMPISTA"(KO mpos kotoran sapi dan kambing, jerami, pistia dan paitan).

https://justkie.wordpress.co $\mathrm{m} /$ tag/kotoran-kambing/ diakses tanggal : 28 Januari 2015

Roihanna, Haryanti dan Hastuti, 2009. Pengaruh Kompos dengan Stimulator EM 4 (Microorganism 4) Terhadap Pertumbuhan dan Produksi Jagung

Manis.http://eprints.undip.ac .id/34269/ diakses tanggal : 30 Januari 2015

$$
\begin{array}{ccc}
\text { Sabrina, } & \text { 2013. EFFECTIVE } \\
\text { MICROORGANISME 4( EM4). } & \frac{\text { http://sutrisarisabrinanaingg }}{\text { olan.blogspot.com/2013/06/ }} \\
\frac{\text { effective-microorganisme-4- }}{\text { em4-normal-0.html diakses }} & \frac{\text { tanggal : 28 Januari 2015 }}{2015}
\end{array}
$$

Sukir, 2010. ANALISIS PEMANFAATAN PENGOLAHAN SAMPAH ORGANIK MENJADI PUPUK KOMPOS.

http://repository.usu.ac.id/h andle/123456789/18910 diakses tanggal : 30 Januari 2015

Wardayu, Tintisnowati Guritno, 2007. Pengolahan Sampah Kubis dan Jerami sebagai Kompos dengan Menggunakan Variasi Starter. 